Haya: The Saudi Journal of Life Sciences

Abbreviated Key Title: Haya Saudi J Life Sci

ISSN 2415-623X (Print) |ISSN 2415-6221 (Online) Scholars Middle East Publishers, Dubai, United Arab Emirates

Journal homepage: https://saudijournals.com/sjls

Review Article

\title{
Novel Methods for Detection of Biological Samples, Current Direction and Future Perspectives
}

\author{
Mahpara Qamar ${ }^{1}$, Ghulam Ammad Mustafa $^{2}$, Sobia Tariq ${ }^{1}$, Hamza Rafeeq $^{1 *}$, Maria Rafiq ${ }^{1}$, Wajahat Zahra Naqvi ${ }^{1}$, \\ Noman Yashir ${ }^{3}$, Rizwana Jabeen ${ }^{1}$, Tooba Kanwal ${ }^{4}$ \\ ${ }^{1}$ Department of Biochemistry, University of Agriculture, Faisalabad, Pakistan \\ ${ }^{2}$ Department of Plant Breeding and Genetics, University of agriculture, Faisalabad, Pakistan \\ ${ }^{3}$ School of Environmental Science and Engineering, Shaanxi University of Science and Technology, Xian, 710021, P.R. China \\ ${ }^{4}$ Department of Chemistry, University of Education, Lahore, Pakistan
}

DOI: $10.36348 /$ sils.2020.v05i11.003

| Received: 29.10.2020 | Accepted: 09.11.2020 | Published: 25.11.2020

*Corresponding author: Hamza Rafeeq

\section{Abstract}

The biosensor tool which is used in the fields of area of a good life such as research related to medicine, public healthcare, in the monitoring of the environment, now a days scientist make more advancement. The modification in the field of technology which is really helpful in the making of the biochip and they provided all of the instrument needed to require make a detection tool, and a system with the micro fluid are place on the chip, sampler, probe, amplifier, detector, and a logic circuit and these biosensor provide the simple, reagent free, label free, monitoring with real time and application with the low cost. In the field of medical this would be very helpful in the production of the low cost detection of the analytic and use in the home such as the glucometer which tell us about the blood glucose concentration and can accordingly administrate the concentration of the insulin in the body, the detection of the disease becomes more easy as we cannot send the sample for the detection in the laboratory which is really time consuming and costly procedure. In the field of environment monitoring biosensor can detect the various target present in the environment, beside from the specialized laboratories and the devices which is portable and development research step from the initial form to its product which require the intention and the collaboration of the different science and technology universities and many other institute of research, stake holder and investor should also pay intention toward the development of these kind of technologies.

Keywords: Insulin, environment monitoring, biosensor, Chip DNA.

Copyright @ 2020: This is an open-access article distributed under the terms of the Creative Commons Attribution license which permits unrestricted use, distribution, and reproduction in any medium for non-commercial use (NonCommercial, or CC-BY-NC) provided the original author and source are credited.

\section{INTRODUCTION}

The bio elements which play important role in the many in the living organism any many kind of the changing take place in the living body if there any change in the these element which cause to various kind of the abnormalities in the individual and such bioelemets are made up of oxygen carbon nitrogen phosphorus and many other element that make up the a living organism these all of the essential elements are necessary for the proper growth of the living organism and all of these elements required for the both of the plants and the animal require in the specific amount and in all of these major elements is present with the amount of the $0.005 \%$ are calcium, magnesium phosphorus e.g this is device which gives results by converting the biological response into the electrical signals, biosensors are very specific in their action and independent from the physical parameter such as the temperature $\mathrm{p} \mathrm{H}$ and are reuse-able again and again and the word the bio sensor introduced by the Camann and IUPAC[1].

Biosensors fabrications, material, devices of the transducing, and the mobilization techniques is required in multi-disciplinary research in various filed of the biology, chemistry and the other field of the biomedical engineering all the material use in the biosensing divided into the three categories in which the very first one is the bio catalytic which is consist of the enzymes, micro based which is consist of the microorganism and the biosensor have great diversity of the application in field of the life such as the tissue based, DNA based, immunosensor, enzyme based, antibody based and many other which play important role in the application of the medical field. The bio sensor are using in the field of the food industry to keep 
the check on the quality of the food and also the safet[2,3].

It is also use to check the concentration of the glucose in the food in metabolic engineering for the in vivo cellular activation, and quality of the food is also checked that it is artificial or the natural. Human heart disease which is caused by the interleukin 10 can be detected by the biosensors, papilloma virus detection are the important aspects of the bio sensing. Cancer is one of the major cause of the death worldwide by using the fluorescent bio-sensing used to find out the presence of the cancer in body and the have great impact in the drug discovery [4].

Lyon and the Clarks was the person who started the bio sensor techniques, now days various types of the bio sensors use in the medical field such as thermal bio sensors. The first sensor of the enzyme based discovered by the Hicks and the Updike in the 1967. This was design on the immobilized method and various kind of the enzyme in this such as the oxidoreductases, poly-phenol oxidase, all of these are worked on the base adsorption of the enzyme which having the different forces such as the van der wall forces, ionic bonding[5].

The first microorganism based bio sensor was advised by the Divies, and for animal and the plant sensors, tissues from the both sources are collected and the inhibitor of analyte. Amino acid. Arginine was the first tissue based was analyzed by the bio sensor method developed .Cell membrane, mitochondria; chloroplast is used to make the organelle based bio detection techniques. In this method very less specificity and the time consuming for the detection of the required elements but results of the stability is very high. The antibody antigen interaction have the great affinity toward each other and play important role in the development of the immune biosensors i. e. each toxin and the pathogen is bind to the specific antibody or to their attachment site where they get attached on the surface of the antigen and cause the neutralization the effect of the antigen[6].

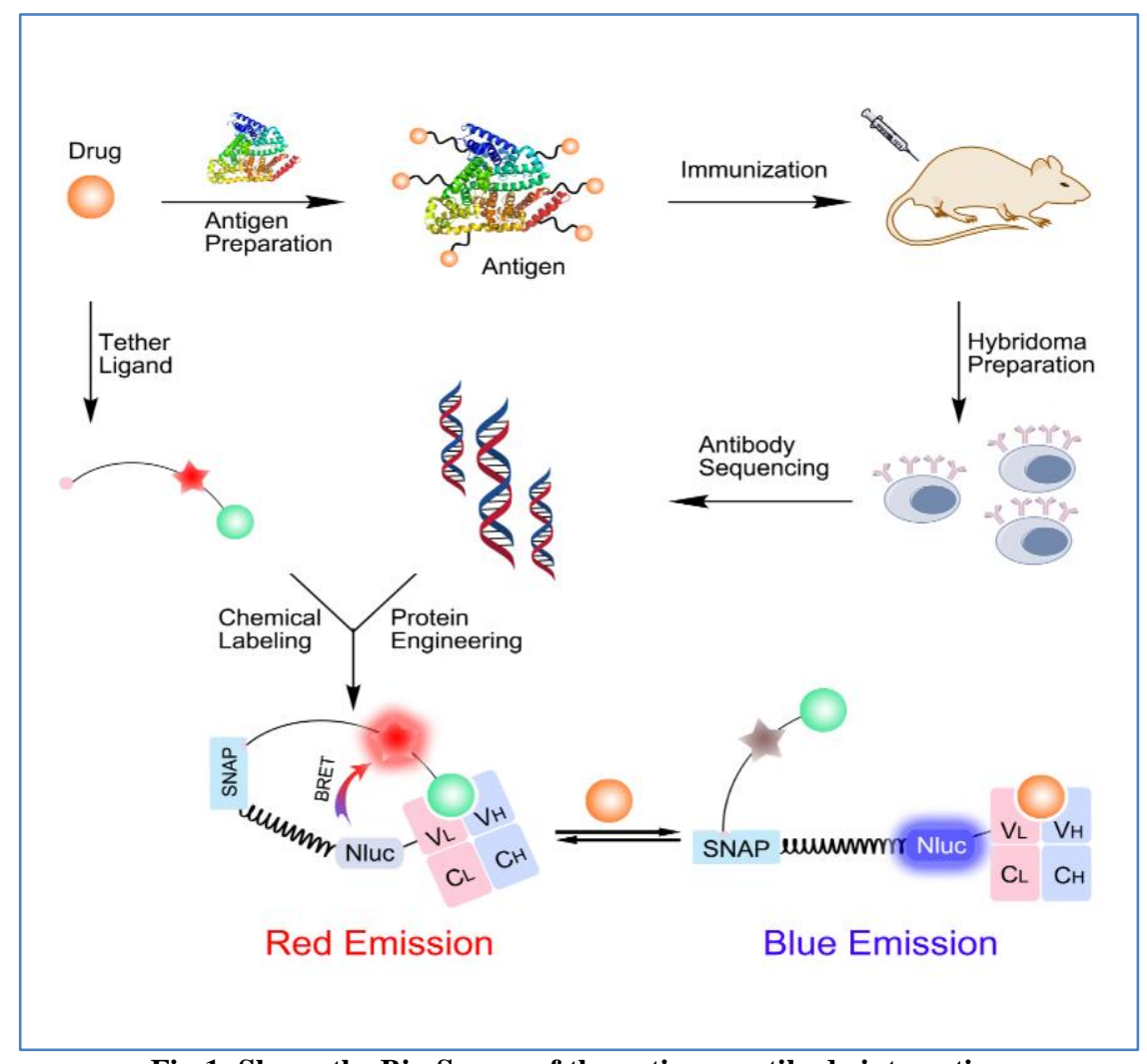

Fig-1: Shows the Bio-Sensor of the antigen- antibody interaction

DNA bio sensor work on the base of the hydrogen bonding the DNA in sample and biosensor DNA make complimentary interaction with each other by sharing the single stand and make the stable hydrogen boding with each other and make stable nucleic acid strand. While considering the biosensor of the magnet it detect the magnetic nano particle and the magnetic micro plate in the channel of the micro fluid effect of magneto resistance show the high potential for the size and the sensitivity by using the transducer of physical apparatus material calorimetric and the biothermal sensor developed and there are two types of the piezoelectric bio sensor a wave device for the acousctic surface and the crystal quartz microbalance, and frequency is the main factor on which we can easily check the measurement of the various crystals, the structure of the crystal and mass is also changed[7]. 


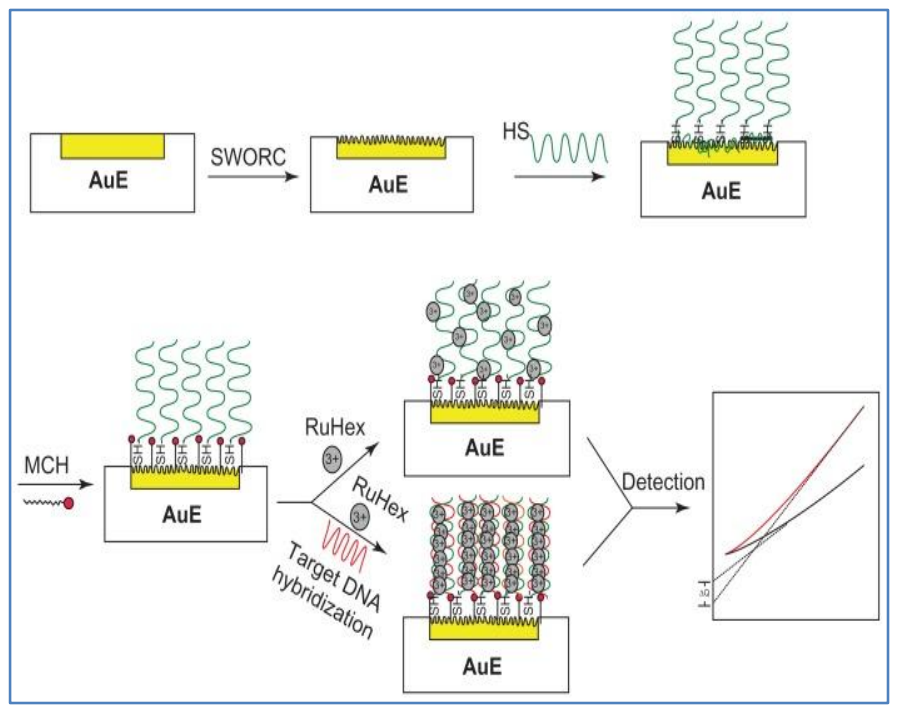

Fig-2: Shows the approach towards of DNA Bio-Sensors

The light source is used in the light bio sensor and a beam of light id generated in the various component of the optical biosensors which have specific in characteristics, the light is used in this used as agent of modulating, in the optical bio sensor the head consist of photo detector. Different flourescent protein green in color and other AFP auto- flurorescent protein have great impact in the development of the biosensors which is genetically encoded. This kind of the biosensor is very easy to manipulate, transfer into the cell, another kind of the biosensors use Is the example of the FRET biosensor of signal change, and these are consist of the a pair of the AFPs that transfer the energy and the Flouresense, in them and brought them closer, many different methods is use to enhance the FRET which is based on the intensity and lifetime ratio. There are many sensors of the protein and the peptide that can be manufactured through using the synthetic sources of the chemistry and labeling is done by the enzyme fluorescence being the independency of the genetically coded theses are used to utilized the activity of the target and alternative attractive which have benefit to increase the noise to signal ratio and response sensitivity checked through the photochemical and the quencher group [8].

There is no doubt about that Otto Warburg was the inventor of the analysis of enzymatic actions. In the 1930s mid he observed the detection of the NADH and NADPH at wavelength of the $340 \mathrm{~nm}$ that was the very sensitive results of the detection of the different dehydrogenases and their various substrates and this done by using the optical test. Different scientist such as Hans and Bergmeyer has developed different commercial enzymes of the optics which is based on the initial Warburg model. Leland $\mathrm{C}$ was the Father of the biosensors he observed that the oxygen is reduced by the using of the different platinum electrode and measure the blood oxygenation and due to the absorbance of the blood on the surface of the electrodes biosensor was got failed which causes the hindrance in the signals. He introduced the new idea of the biosensor development by using the wrapper of the cell phone and the packet of the cigarette. This method was useful only for the low molecular weight atoms such as oxygen which can easily pass from the and can be measured easily [9].

The current of the reduction can be used for the indication of the concentration of the oxygen then electrode of the Clark was created. Now a days membrane of teflon used and very useful in the monitoring of the environment and the medicinal tool. Glucose oxidase was use in the solution as the indicator the further development in the sensor by add in the solution the another semi permeable membrane in the electrode front. The glucose oxidase can be used again for the further measurement. On the layer of the electrode it becomes the part of the sensor and Lee want to denote the name this electrode enzyme electrode which is shown in fig. 1.3 in the meeting of USA in 1962. The instrument known as the YSI yellow springer instrument was invented after some time which is used to analyse the glucose and the anme of this analyzer was the YSI 23006 and then the monitoring of the oxygen through the electrochemical detection of the oxygen and the hydrogen peroxide. In the 1973 YSI was the launced and there are many problems in with draw then there was the solution for the problem to add the membrane and with the few modification company develops the many series of the analyzer around the 1975. After these invention there many other instruments was the invented such as the urea electrode which was highly potentiometric and immobilized urease was used which was really $\mathrm{pH}$ sensitive. The first lactate sensor was invented by the mind and the Racine in this method artificial redox mediator replaced with the cytochrome B2 [10].

Various biological and the chemical techniques in which different reactions take place in the solutions with the adding of the reagent in the sample 
solution, but in these recent years there are many progress can be seen in the in the reagent less system fit. The new system in which the different reagents are already attached or immobilized on the system and there is no any need to be added in the solution by the operator. In the biosensor reaction take place on the surface of the electrode. The definition of the biosensors are the in which the transducer are integrated with the analyte which is close proximity in the interference, and these are directly depend upon the interaction of the analyte with their mediator. The biological analyte may be any substance such as the different immobilized enzyme, micro bodied and the antibodies, all of the make interactions with their specific compatible substance which enhance the sensitivity and specificity of the various device on which these are being used. Transducer play very important role in the generating the electrical signals from the biological substance and output can be easily get by the simply processing [11].

In the bio detection technologies bio sensors are the tools which is very low in the cost and gve rapid detection and very easy to handle and therefore play very important role in the health care and in the different emerging technologies and in the different analysis. Bio sensor work likes such as enzyme interaction with their substrate and bio sensors have the high specificity and the sensitivity which gives the different indications of the various product. The bioelements which is really fragile show the real time analysis and have to measured very quickly, it play major role in the different care analysis related to the health, and the concept of these biosensor started in the 1962, Clark and their coworkers introduced the first enzyme detection electrode for the detection of the electrochemical from the different enzyme solution and specific analyte can be detected [12].

The Biosensors are the compounds which are functional analogs and based on coupling direct with an immobilized compound which is the biological in nature when added in solution make contact direct with the analyte and then amplify the signal with the electronic amplifier. The interaction between these molecules which convert the simple signals into electrical signals which is shown in fig 1.4 in which general configuration of the biosensor is given and different classification of the biosensors are given such as the calorimetric, optical, electrochemical and piezoelectric, in the optical biosensor the beam of light Is used detectors are used to analyzed or measured the value. Biosensors can be used for the different measurement of the $\mathrm{CO} 2$ and $\mathrm{O} 2$ and the $\mathrm{pH}$. Optical biosensor which can be used for the Commercial which is highly electrochemical and optical that was invented by the Pal. Different biosensor work on the basis of the heat such as the calorimetric biosensor, in the calorimetric enzyme and analyte interaction take place, the modification in the bio sensors with the adding of the temperature sensitive structure. Different kind of antigens, enzymes, and the vitamins can be determined through the biosensor of the thermometric and probe are the most commonly used approaches. Which is related to somehow enzymes that attached directly on the thermistor. In the enzymatic reaction most of the heat is evolved in the surrounding and cannot be detected by the thermistor which causes the decrease sensitivity of the sensor the most commonly used bio sensor that used are the electrochemical bio sensor. They have overcome disadvantage in which many other types of the biosensors is used and these are very easy for handle and rapid in action and low in cost [12].

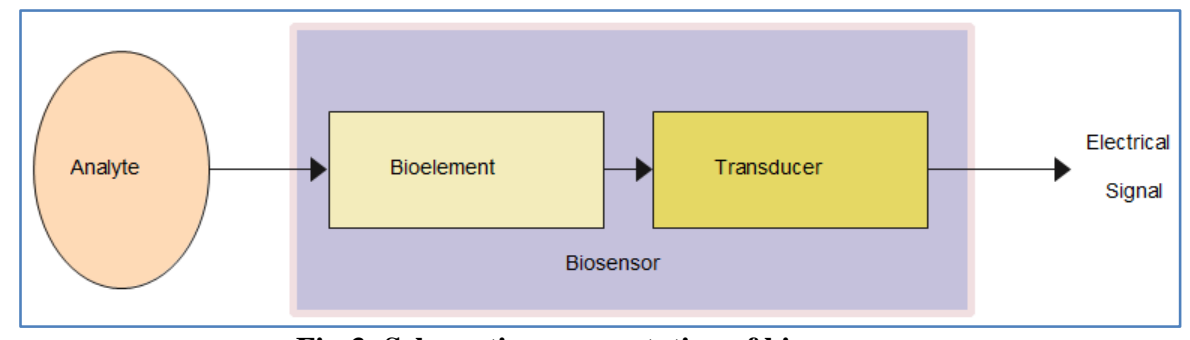

Fig-3: Schematic representation of biosensors

\section{Application of the biosensor}

The term biosensor which is consist of an element and a transducer which is very sensitive in their action, and is a very versatile too used in the many fields, such as in the safety and quality of the food, medicine, monitoring the pollution in the environment, and diagnostic fields, the quality of life in which the bio sensor play very important role in this present report the application and type of the biosensor is discussed, the application and the new design to develop the new instrument related to the field of the bio detection technologies, medical sample, industries, improving the quality of food, detection of disease. All the biosensor work on the different principles but in all of the biosensor the signal is detected and amplify with the help of the transducer and all show the great specificity, selectivity, sensitivity, in all the biosensor the required molecule can easily be detected without having any kind of disturbance [14].

Medicinal Application of the enzyme base bio sensor Many of the elements which is recognizable and when combine with the transducer they achieved their required target in the field of the bio medical 
industries, the biosensor that work on the base of enzyme give the most successful results. The enzyme based bio sensor having the many application in different such as the in vivo detection of the glucose measuring inside the human blood and a single cell level reaction can be measured accurately. In this fields two areas of the research are difficult to achieve and take the long time, the enzyme base biosensor have 4 biggest advantage over the traditional and analytical methods, that having the feat future in the field of biomedical research which given, biosensor are more susceptible to the miniaturization and having the great deal of importance because there are very small amount of biological molecule is present and in treating with in vivo the minimum damage of the tissues made possible, prior separation is very necessary for the key substrate detection, short time response are characterized by the biosensors, and can easily be used, but few of the enzyme based biosensor show the some drawbacks as compared to the many other analytical tools, the major and difficult problem to solve for biosensor that having applications in the field of biomedical are, reduced in the stability of enzyme, and not place in the natural environment in which enzyme lose activity very fast and the biosensor lifetime become limited[15].

The composition of the matrix is very complex so chances of electrochemical interference become more and more so there is need to modify the surface of electrode in such a way that biosensor can detect on the base of single process of the biosensor which is a very difficult task, biofouling and the biocompatibility are the critical and major issue in vivo measurement. The enzyme based biosensor met with many requirements of the biomedical field. The first enzyme based biosensor glucose biosensor I which scientist show great deal of interest. The patients of diabetes were large in number and the best way to control the number condition of patients to measure the level of the blood glucose level and administration of the insulin the patents of diabetes. Now a days glucose detection biosensor commonly known as the enzyme base biosensor are the portable can easily be transfer from one place to another, also have the cheap cost that is very helpful for the patients of diabetes to check the glucose level of blood at their home[16-18].

\section{Biosensor application in Agriculture}

The quality of life and maintain the healthy life style food play very important role, the quality of the food and the consumers which require healthy and sophisticated life style in which the chain of distribution, processing and the production carefully observed. However it is very critical to trace the contamination present in source of food. Thus there is lot of precaution need to process in the industries that should be rapid, simple and affordable. In the bio detection techniques most of the producer which use the analytical techniques such as the chromatography, spectrophotometry, which is usually not easy and not the continue source of monitoring [19-21].

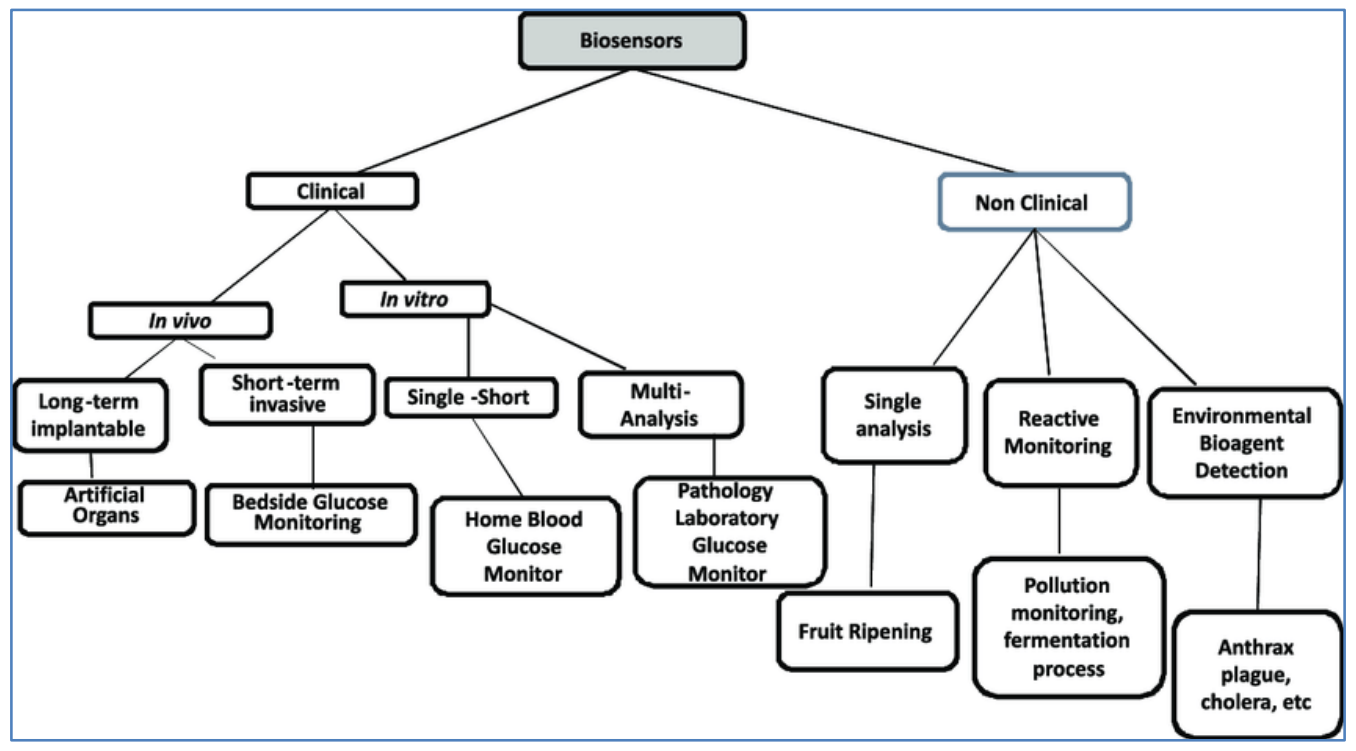

Fig-4: Shows the Application of the biosensor

An alternative method can be used with the help of the biosensor which is used in the analytical method aside the low cost and the specificity the biosensor can easily be placed on the automation scheme and also can produce the simple and the portable equipment, in which we csn easily monitor the material which is raw in nature and can check the quality and safety of the food which is far step from here [22-25]. Furthermore in the developing countries biosensor give promising application and now a days there are many publication is done on the biodetection techniques and the sensors some of the drawback of the bio detection which is the there is very less time for the biological molecule, a mediator on which this is diffuse, coenzyme require for its function, and can easily be handle [26-30]. 


\section{Applications of biosensors in Agricultural monitoring}

In the present year in the developing countries such as the Pakistan the environment has the major impact on the human health and also can say that is directly linked with the life style of the individuals, for the target analyte there is need to be selective, sensitive and the qualitative and quantitative need of measurement of the analyte in the solution [31-34]. There are many kind of the techniques available yet but requirement is cheapest in cost, analysis with in the short time, simplicity, rapid detection, and reliability all of these cannot be achieved by the single method of detection, but the techniques which is based on the recognition of the biological molecule can met with many of the requirement that having the high specificity, selectivity, and interaction of speed between the component of the biological cell itself [35-38].

In the types of the biosensor many types of the biosensor had been develop for the compound determination belong to or relevance with the environment such as the aromatic amine and the phenols metal and the pesticides there is long ago to determine the complete information about the biosensors. In the biosensor the interaction between the biological molecules take place that may be kid of enzyme and the receptors which is really dangerous for the health. The heavy metals which are highly stabilized make the complex of the metals cannot be recognized by the biological molecule are really harm for the living organism and mostly bound are present. The metals play very important and integral role in the living organism such as the cobalt, calcium, copper, chromium, potassium, sodium, magnesium, manganese, zinc, nickel act as the nutrient and some of the metals play doesn't have any role in the biological organism such as the cadmium, aluminum, gold, and lead. The metal which play essential role and act as the catalyst and also stabilize the structure of biological molecule such as the bacterial cell wall and the proteins. The metals in the high concentration cause the toxicity in the blood $[39,40]$.

\section{CONCLUSION}

In past decades the advancement in the field of bio sensor and the bio technologies which have great impact in the life style of the human being in many ways. The biosensor are very efficient in their action and mostly meet the need and requirements which is really sophisticated and analytical method and some of the biosensor which is design very firstly to detect the specific analyte in the concentration such as the neurotransmitters which have the great importance in the field of medical research, with the help of the biosensor we can detect the single cell level, quality and the safety of the agricultural product is checked.

\section{REFERENCES}

1. Acha, S., Green, T. C., \& Shah, N. (2010). Effects of optimised plug-in hybrid vehicle charging strategies on electric distribution network losses. In IEEE PES T\&D 2010 (pp. 1-6). IEEE.

2. Akyilmaz, E., Yorganci, E., \& Asav, E. (2010). Do copper ions activate tyrosinase enzyme? A biosensor model for the solution. Bioelectrochemistry, 78(2), 155-160.

3. Aye-Han, N. N., Ni, Q., \& Zhang, J. (2009). Fluorescent biosensors for real-time tracking of post-translational modification dynamics. Current opinion in chemical biology, 13(4), 392-397.

4. Belkin, S., \& Gu, M. B. (Eds.). (2010). Whole Cell Sensing System II: Applications (Vol. 118). Springer Science \& Business Media.

5. Bhatta, B., Saraswati, S., \& Bandyopadhyay, D. (2010). Urban sprawl measurement from remote sensing data. Applied geography, 30(4), 731-740.

6. Biran, J., Ben-Dor, S., \& Levavi-Sivan, B. (2008). Molecular identification and functional characterization of the kisspeptin/kisspeptin receptor system in lower vertebrates. Biology of reproduction, 79(4), 776-786.

7. Brett, M., Andersson, J., Wager, T., \& Poline, J. B. (2005). Valid conjunction inference with the minimum statistic. Neuroimage, 25(3), 653-660.

8. Ercole, C., Del Gallo, M., Mosiello, L., Baccella, S., \& Lepidi, A. (2003). Escherichia coli detection in vegetable food by a potentiometric biosensor. Sensors and actuators $B$ : Chemical, 91(1-3), 163-168.

9. Usman, G., Muhammad, N., Hamza, R., Usman, I., Ayesha, A., Saqib, U., \& Fatima, Q. (2019). A Novel Approach towards Nutraceuticals and Biomedical Applications. Scholars International Journal of Biochemistry, 2(10), 245-252.

10. Ahsan, M., Aslam, M., Akhtar, M. A., Azmi, U. R., Naeem, M., Murtaza, G., ... \& Shafiq, S. (2019). Effect of inoculation of three rhizobial strains on maize hybrids. Journal of Biodiversity and Environmental Sciences, 14(6), 168-177.

11. Naeem, A., Saddique, S., \& Chand, S. A. (2019). Advancement and Future Directions towards Herbal Treatment for Various Diseases.

12. Naeem, M., Hussain, A., Azmi, U. R., Maqsood, S., Imtiaz, U., Ali, H., \& Ghani, U. (2019). Comparative Anatomical Studies of Epidermis with Different Stomatal Patterns in Some Selected Plants Using Compound Light Microscopy. International Journal of Scientific and Research Publications, 9(10), 375-380.

13. Naeem, M., Ashraf, A., Safdar, H. M. Z., Khan, M. Q., Rehman, S. U., Iqbal, R., ... \& Ahmad, G. Biochemical changes in patients with chronic kidney failure in relation to complete blood count and anemia.

14. Cammann, K. (1977). Bio-sensors based on ionselective electrodes. Fresenius' Zeitschrift für Analytische Chemie, 287(1), 1-9. 
15. Cass, A., \& Ngo, L. V. (2007). Market orientation versus innovative culture: two routes to superior brand performance. European Journal of Marketing.

16. Caygill, R. L., Blair, G. E., \& Millner, P. A. (2010). A review on viral biosensors to detect human pathogens. Analytica chimica acta, 681(12), 8-15.

17. Conroy, C., Gunn, J. E., \& White, M. (2009). The propagation of uncertainties in stellar population synthesis modeling. I. The relevance of uncertain aspects of stellar evolution and the initial mass function to the derived physical properties of galaxies. The Astrophysical Journal, 699(1), 486.

18. Hussain, A., Rafeeq, H., Asghar, A., Ullah, S., Imtiaz, U., Ullah, H., \&amp;amp; Ilyas, M. D. Combined inhibitory potential of Ammonium thiosulphate and 2-chloro- (trichloromethyl) pyridine on ureases activities.

19. Muhammad, N., Muhammad, M., Asim, U., Siraj, A., Ghafoor, A., Jabir, A., Sayed, J. R. Z., Muhammad, Z.H., Tania, Z., Irfan, K. (2019). New trends in removing toxic metals from drinking and wastewater by biomass materials and advanced membrane technologies. J. Bio. Env. Sci. 15(3), 1017.

20. Rafeeq, H., Arshad, M. A., Amjad, S. F., Ullah, M. H., Muhammad, H., Imran, R. K., ... \&amp;amp; Ajmal, H. Effect of Nickel on Different Physiological Parameters of Raphanus Sativus.

21. Rafeeq, H., Tanvir, K., Khan, M. A. B., Basit, I., Ul, Q., Ain, F. F., ... \& amp; amp; Siddique, S. An Effective Approach towards Heavy Metals and their Effects on Different Organs of the Body.

22. Hussain, A., Nashat, N., Liaqat, A., Waheed, M., Aslam, M., \& Asif, N. A Comprehensive Review on Diabetic Retinopathy and Mental Disorders.

23. Salman, M., Saba, Q., Asim, H., Asma, A., Rubab, S., Sara, Z., Noman, N. (2020). Antifungal Properties of Copper Nanoparticles against Aspergillus niger. Scholars International Journal of Biochemistry, 3(4): 87-91.

24. Ahmad, I., Khan, S., Naeem, M., Hayat, M., Azmi, U. R., Ahmed, S., \& Irfan, M. (2019). Molecular Identification of Ten Palm Species using DNA Fingerprinting. Int. J. Pure App. Biosci, 7(1), 4651.

25. Rafeeq, H., Ahmad, S., Tareen, M. B. K., Shahzad, K. A., Bashir, A., Jabeen, R., ... \& Shehzadi, I.(2019). Biochemistry of Fat Soluble Vitamins, Sources, Biochemical Functions and Toxicity.

26. David, P. A. (2008). The Historical Origins of'Open Science': an essay on patronage, reputation and common agency contracting in the scientific revolution. Capitalism and Society, 3(2).

27. Bukhari, S. A. B. H., Akhtar, M. W., Rehman, S. U., Akhtar, W., Rafeeq, H., Ashraf, A., ... \& Aslam, N. A Novel Approach towards the
Identification of plant genes, Bioinformatics Analysis and Role of EIN3 and EIL1 in plants.

28. Rafeeq, H., Ahmad, S., Tareen, M. B. K., Shahzad, K. A., Bashir, A., Jabeen, R., \& Shehzadi, I. Biochemistry of Fat Soluble Vitamins, Sources, Biochemical Functions and Toxicity.

29. David, P. A. (2008). The Historical Origins of'Open Science': an essay on patronage, reputation and common agency contracting in the scientific revolution. Capitalism and Society, 3(2).

30. Naeem, M., Ali, J., Hassan, M. Z., Arshad, B., Rao, M. H. I., Sarmad, M. S. K., ... \& Hussain, M. U. Novel Approach towards DNA Barcoding as a Tool in Molecular Biology and Biological Activities of Cyclotides with Particular Emphasizes at Molecular Level.

31. Dodeigne, C., Thunus, L., \& Lejeune, R. (2000). Chemiluminescence as diagnostic tool. A review. Talanta, 51(3), 415-439.

32. D'Orazio, P. (2011). Biosensors in clinical chemistry-2011 update. Clinica Chimica Acta, 412(19-20), 1749-1761.

33. Fowler, J. H., \& Christakis, N. A. (2008). Dynamic spread of happiness in a large social network: longitudinal analysis over 20 years in the Framingham Heart Study. Bmj, 337, a2338.

34. Shafiq, S., Adeel, M., Raza, H., Iqbal, R., Ahmad, Z., Naeem, M., \& Azmi, U. R. (2019). Effects of Foliar Application of Selenium in Maize (Zea Mays L.) under Cadmium Toxicity. In Biological Forum-An International Journal (Vol. 11, No. 2, pp. 27-37).

35. Naeem, M., Hayat, M., Qamar, S. A., Mehmood, T., Munir, A., Ahmad, G., \& Hussain, A. (2019). Risk factors, genetic mutations and prevention of breast cancer. Int. J. Biosci, 14(4), 492-496.

36. Grubor, B., Gallup, J. M., Meyerholz, D. K., Crouch, E. C., Evans, R. B., Brogden, K. A., ... \& Ackermann, M. R. (2004). Enhanced surfactant protein and defensin mRNA levels and reduced viral replication during parainfluenza virus type 3 pneumonia in neonatal lambs. Clin. Diagn. Lab. Immunol., 11(3), 599-607.

37. Mono, M. L., Fischer, U., Findling, O., Weck, A., \& Mattle, H. P. (2012). Endovascular therapy of 623 patients with anterior circulation stroke. Stroke, 43(4), 1052-1057.

38. Munteanu, M. I. (1998). CR-structures on the unit tangent bundle and Bochner type tensor. To appear.

39. Nies, D. H. (1999). Microbial heavy-metal resistance. Applied microbiology and biotechnology, 51(6), 730-750.

40. Parkinson, G., \& Pejcic, B. (2005). Using Biosensors to detect emerging infectious diseases. Prepared for The Australian Biosecurity Cooperative Research Centre, 1-80. 